\title{
Intraneural lipoma of the ulnar nerve at the elbow: A case report and literature review
}

\author{
Anila Balakrishnan $\mathrm{MD}^{1}$, Yeon Jen Chang $\mathrm{MD}^{2}$, David A Elliott $\mathrm{MD}^{2}$, Chenicheri Balakrishnan $\mathrm{MD}^{2}$
}

\begin{abstract}
A Balakrishnan, YJ Chang, DA Elliott, C Balakrishnan. Intraneural lipoma of the ulnar nerve at the elbow: A case report and literature review. Can J Plast Surg 2012;20(3):e42-e43.

Intraneural lipomas of the ulnar nerve or its branches are rare benign tumours. Although most intraneural lipomas present as asymptomatic tumours, some may present as compression neuropathies due to their location. In the majority of cases these tumours can be enucleated without damage to the nerve fibres.
\end{abstract}

\section{Un lipome intraneural du nerf ulnaire au niveau du coude : rapport de cas et analyse bibliographique}

Les lipomes intraneuraux du nerf ulnaire ou de ses branches sont des tumeurs bénignes rares. Même si la plupart des lipomes intraneuraux sont asymptomatiques, certains peuvent s'associer à des neuropathies de compression attribuables à leur foyer. Dans la majorité des cas, on peut énucléer ces tumeurs sans endommager les fibres nerveuses.

Key Words: Intraneural lipoma; Ulnar nerve

\begin{abstract}
Intraneural lipomas and lipofibromas of the ulnar nerve are rare soft tissue tumours causing progressive compression neuropathy. Pathological lesions include neurilemmomas arising from the neural sheath and neurofibromas that are centrally placed, with nerve fibers traversing the tumour mass. Nerve tumours that are intraneural in location but non-neural in origin include fibrofatty infiltrate, intraneural lipomas, hemangiomas and ganglion cysts. The term lipofibromatous hamartoma was introduced by Johnson and Bonfiglio (1) to describe a diffuse lipofibromatous infiltration of a nerve. These may occur as well encapsulated or diffusely infiltrative tumours. The well encapsulated tumours occur most commonly in women in their $40 \mathrm{~s}$ and 50s. Due to its rare occurrence, the present article describes a case of intraneural lipoma of the ulnar nerve at the elbow that presented as compression neuropathy.
\end{abstract}

\section{CASE PRESENTATION}

A 48-year-old woman presented with a two-year history of progressive weakness and numbness of her nondominant left hand. She described decreased feeling in the fifth digit of her left hand. Her medical history was significant for asthma and hypertension, and she had recently gained weight due to a course of steroid treatment for her asthma. On examination, weakness of her intrinsic muscles and decreased twopoint discrimination of the fifth digit of the left hand were observed. An electromyogram and nerve conduction studies showed a slowing of conduction of the ulnar nerve at the elbow, with normal muscle function and no evidence of peripheral neuropathy. Radiographs of the elbow were negative. At exploration (Figure 1), there was a well encapsulated lipoma along the whole length of the ulnar nerve in the cubital tunnel at the elbow. The lipoma was removed from the length of the ulnar nerve at the elbow with anterior subcutaneous transposition of the ulnar nerve. Histology identified the mass as a benign lipofibroma. The patient regained full sensory and motor function postoperatively.

\section{DISCUSSION}

Most peripheral nerve tumours arise from the supporting cells of the nerve. The masses are usually slow-growing and may cause nerve compression resulting in sensory change, pain and loss of motor function. Four types of lipomatous masses associated with peripheral nerves have been identified: soft tissue lipoma, intraneural lipoma, macrodystrophia lipoma and lipofibromatous hamartoma. Soft tissue lipomas are true benign neoplasms that originate from adipose cells and can cause

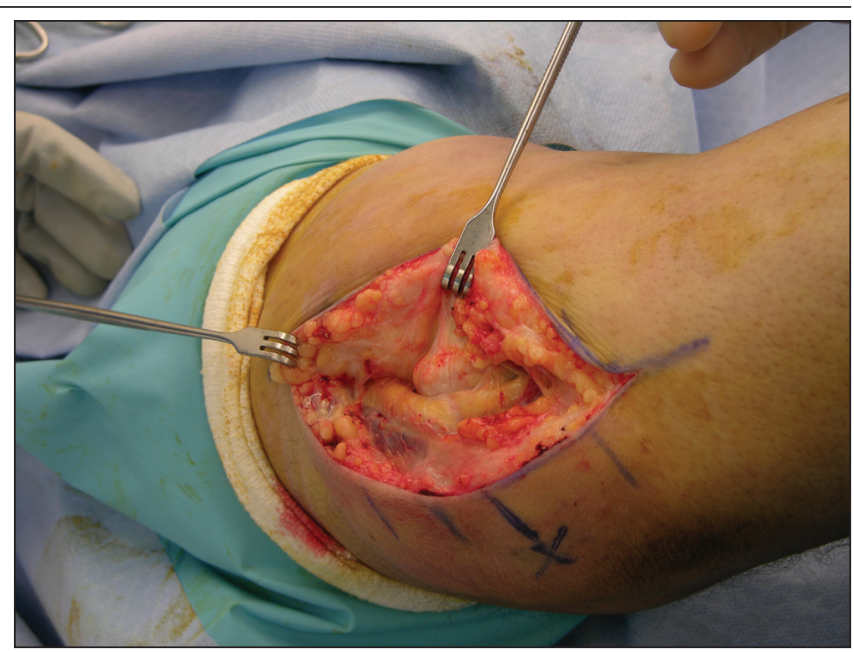

Figure 1) Intraneural lipoma at the elbow at exploration

peripheral nerve compression extrinsically. Intraneural lipomas arise from adipose cells within the nerve.

The origin and pathogenesis of lipofibromatous hamartomas are unknown, although repetitive microtrauma resulting in reactive fibrofatty cell proliferation has been suggested. A lipofibromatous hamartoma is a gross enlargement of the nerve caused by fat and fibrous tissue, with epineural and perineural proliferation. These masses may be encapsulated or infiltrative in nature. The majority of cases have been reported to occur in the median nerve at the wrist, hand or distal forearms, but lipofibromatous hamartomas in other locations, including the ulnar nerve, the radial nerve and the sciatic nerve have also been reported. The majority of the reported peripheral nerve tumours of the upper extremity involve the median nerve. Symptoms are usually due to compression of the nerve at the fibro-osseous tunnel (2-8).

The majority of the reported cases of intraneural lipomas of the ulnar nerve presenting as compression neuropathies have been reported at the wrist (9-12). Most of these cases presented as slow growing tumours, with symptoms developing over time. Symptomatic lipofibromatous hamartomas of the ulnar nerve have been reported at the elbow (13). Although rare, other soft tissue tumours causing 
compression neuropathy include ganglion cysts and muscle tumours. The ganglion cysts of peripheral nerves may be extraneural or intraneural. Intraneural ganglia may be difficult to separate from the neural elements without resultant nerve injury. Ganglion cysts confined to the epineurium of the ulnar nerve at the elbow causing neuropathy have also been reported (14).

The patient in the present article presented with a slowly progressive compression neuropathy of the ulnar nerve. Electromyography confirmed the compression at the elbow. At exploration, the nerve was found to be covered with fat. Surgical enucleation of the lipoma resulted in complete sensory and motor recovery.

\section{REFERENCES}

1. Johnson RJ, Bonfiglio M. Lipomatous hamartoma of the median nerve. J Bone Joint Surg Am 1969;51:984-90.

2. Chiao HC, Marks KE, Bauer TW, Pflanze W. Intraneural lipoma of the sciatic nerve. Clin Orthop Relat Res 1987;221:267-71.

3. Abu Jamra FN, Rebeiz JJ. Lipofibroma of the median nerve. J Hand Surg 1979;4:160-3.

4. Camilleri IG, Milner RH. Intraneural lipofibroma of the median nerve. J Hand Surg Br 1998;23:120-2.

5. Phelan GS, Kendrick JI, Rodriguez JM. Lipoma of the upper extremity causing nerve compression. Am J Surg 1971;121:298-306.
6. Strickland JW, Steichen JB. Nerve tumors of the hand and forearm. J Hand Surg 1977;2:285-91.

7. Rusko RA, Larson RD. Intraneural lipoma of the median nerve case report and literature review. J Hand Surg Am 1981;6:388-91.

8. Terzis JK, Danel RK, Williams HB, Spencer PS. Benign fatty tumors of the peripheral nerves. Ann Plast Surg 1978;1:193-216.

9. Galeano M, Colonna M, Ristango G. Ulnar tunnel syndrome secondary to lipoma of the hypothenar region. Ann Plast Surg 2001;46:83-4.

10. Zahrawi F. Acute compression neuropathy of Guyon's canal resulting from lipoma. J Hand Surg Am 84;9:238-9.

11. McFarland GB Jr, Hoffer MM. Paralysis of the intrinsic muscle of the hand secondary to lipoma in Guyon's tunnel. J Bone Joint Surg Am 1971;53:375-6.

12. Balakrishnan C, Saini MS, DeMercurio J. Intraneural lipoma of the ulnar nerve: A case report and review of literature. Can J Plast Surg 2006;14:49-50.

13. Gouldesbrough DR, Kinny SJ. Lipofibromatous hamartoma of the ulnar nerve at the elbow: Brief report. J Bone Joint Surg Br 1989;71:331-2

14. Ferlic DC, Ries MD. Epineural ganglion of the ulnar nerve at the elbow. J Hand Surg 1990;15:996-8. 